\title{
Determining Participating Factors In Physical Education/Sporting Activities Of The Deaf: A Study Of Savelugu School For The Deaf
}

\begin{abstract}
This research examined the determining factors in participating in Physical education/sports activities by the Deaf in Savelugu School for the deaf in Northern region of Ghana. A survey research design was used for the study. A questionnaire and an observation guide were used to solicit information on the determinants of participating in Physical education/sports by the Deaf in Savelugu School for the Deaf. The questionnaire was administered to one hundred and fifty (150) students. One hundred and twenty-four (124) were retrieved. 91\% of the respondents indicated that participating in physical education activities improves on their lifestyles, promotes fundamental motor skills and physical fitness. However, the results indicated that an unsafe environment, family factors, and sports facilities/equipment determined the participation of students in physical activities. The study recommends that adequate modern and modified sports facilities and equipment should be provided to special schools. The Ministry of Education (Special Education Unit) should monitor the allocation of funds and utilization of physical education programmes. Well trained and qualified physical education professionals must be sent to Deaf schools. The study provides us an opportunity to gain insight on how exposed or porous schools for the Deaf are in Ghana in terms of physical/sports activities.
\end{abstract}

\author{
SHANUNU ZAKARIA, \\ IDDRISU SULEMANA, \\ ALHASSAN IMORO NUHU ${ }^{1}$ \\ ${ }^{1}$ Shanunu Zakaria, $P h D$, is a Senior \\ PE Tutor and an Assessment officer \\ at the Tamale College of Education, \\ Ghana.Email: zakariashanunu@ \\ gmail.com. Iddrisu Sulemana, PhD \\ is the Principal of Tamale College \\ of Education and Vice President of \\ PRINCOF.Email: sulesakabu@yahoo. \\ com. Alhassan Imoro Nuhu, M,Ed, is \\ the Vice Principal of Tamale college of \\ Education and a Tutor in the \\ Mathematics Department. \\ Email: imoronuhu@gmail.com. \\ Manuscript \\ Received 14th April 2020, \\ Accepted 22nd May 2020, \\ Published online 27th May 2020.
}

Keywords: Deaf, Special Education, Disability, Physical activity.

\section{INTRODUCTION}

Globally, physical activities/sports are very popular among the youth and the aged; this is because many nations and societies have realized that it is the key towards healthy developments of the citizens. ${ }^{2}$ According to Moschetti, a sport is an institutionalized competitive activity that involves vigorous physical exertion or the use of complex physical skills. ${ }^{3}$ This is often undertaken by individuals who are motivated by either the intrinsic satisfaction with the activity itself or the external reward earned through participation.

Odejide, indicated that sport and physical activity is a highly organized and patronized activity, with institutions involved in crafting rules and regulations governing physical activity both internally and externally. ${ }^{4}$ Akinsanmi, concurred that sports is playful, competitive, requiring growth and development of an individual and the society. ${ }^{5}$ Sports require long periods of training and physical exertion in order to condition the athlete to perfect the skills and strategies he/she stressed. Individuals who are marginalized are often relegated to the background and therefore sometimes face

\footnotetext{
Odejide,Sports as an Essential Ingredient to National Development.Journal of The Nigeria Academy of Sports Administration 1. (2012): 34- 40

Moschetti,“The Determinants of Sport Participation in Switzerland.” Schweizer ZeitschriftFürSoziologie, 36, (2010): 259-276.

Odejide,Sports as an Essential Ingredient to National Development.

Akinsanmi, T. "The roll of Exercise in promoting Health as perceived by health professionals." Journal of Reseach in Behavioural Sciences 1(2. ),(2015): 34-40.
} 
barriers to participation in sporting activities. ${ }^{6}$ Lack of participation often leads to the inability to take control over one's own life and health.

The World Health Organisation indicated that, health is not only the absence of disease but also the presence of sound physical, social and psychological wellbeing, lack of participation in any given situation leads to feelings of inferiority. ${ }^{7}$ These feelings further lead to lack of self-esteem and a perception of low self-image. Such feelings adversely affect the psychological and social health of a person. McWilliam noted that education of the disabled in Ghana commenced with the blind in 1936 at Akuapem-Akropong in the eastern region. ${ }^{8}$ In 1957 a school was started for the deaf at Osu in Accra. From 1965 onwards, there was expansion in basic education for the deaf all over the country, they added. Savelugu School for the deaf was established in 1978 and located in Savelugu in the Northern region of Ghana.

In Ghana, there are categories of persons with disability and education of the Deaf in Ghana falls under Special Education. Smith as cited in Avoke, explains special education as, "a set of instructions that is individually tailored to meet the unique needs of a child with exceptionality, taking into account the child's individual learning strength and weakness rather than following one set of curriculum as regular education does. ${ }^{9}$ It is a known fact; the Ghanaian society is one in which people are yet to accept differences in terms of disabilities. ${ }^{10}$ Therefore, persons with disabilities, particularly the deaf are highly discriminated against; also, communication remains the greatest barrier for the deaf. With this background, this study seeks to examine other barriers that determine participation of students in physical education and sporting activities in the Savelugu School for the deaf.

\section{SPECIAL NEEDS AND DISABILITY}

Special Education can be seen in so many ways by different professionals, it is so because different professional are interested in the field of study. Professionals in medicine, sociology, education and psychology have their ways of defining the term special education. From the point of view of educationist like Heward \& Orlansky indicated that, it can be viewed as individually planned, systematically implemented and carefully evaluated instructions to help exceptional learners achieve the greatest possible personal self-sufficiency and success in present and future. ${ }^{11}$

Disability is synonymous to impairment, which refers to the loss or greatly reduced ability to perform a function or some functions due to damage or loss of a body part or organ. ${ }^{12}$ World Health Organization report indicates that 'disability results from the interaction between persons with impairments and attitudinal and environmental barriers that hinder their full and effective participation in society on an equal basis with others. ${ }^{13}$ This means that disability is not an attribute of the person but progress on improving social participation can be made to address the barriers which hinder the persons with disabilities in their day to day lives.

\section{Deaf culture}

This is a set of social beliefs, behaviours, art, literary traditions, history, values, and shared institutions of communities that are influenced by deafness and the use of sign language as the main means of communication. ${ }^{14}$ Members of the Deaf community tend to view deafness as a difference in human experience rather than a disability or disease ${ }^{15}$ Many members take pride in their Deaf identity. Deaf people, in the sense of a community or culture, can then be seen as a minority group, and therefore some who are a part of this community may feel misunderstood by those who have no knowledge of sign language. Another struggle that the Deaf community often face is that educational institutions usually consist primarily of hearing people. Laneet'al, agreed that there are several perspectives on deaf people and Deaf culture that shape their treatment and role in society. ${ }^{16}$ From a social standpoint, Deaf are welcomed to participate in society in the same manner as any other individual. But from a cultural perspective, some cultures do not welcome this idea. This view discourages the idea that those who are Deaf are sick and in need of a cure. The social view also encourages making accommodations for Deaf people so that they can fully participate in society. Such accommodations

\footnotetext{
Avoke, M. "Introduction to special education for Universities and Colleges.". City Publishers Accra- Ghana (1997): 1-5, 79-84 WHO. Designing the road to better Health. Constitution, NY: Hasting center 21(1948).

McWilliam, H.O.A. \& Kwamena-Poh, M.A. The development of Education in Ghana.Longman group Ltd : London U.K (1975):41-52.

9 Avoke, M. Special Educational Needs in Ghana: Policy, Practice and Research.Winneba,Special Educational Books: Winneba Ghana.(2005) $: 1-6$.

10 Ibid.

11 WHO, http://www.who.int/disability/worldreport/2011/report/en/index.html 2011

12 Prosper, D. \& Gyimah, E. Educating the Special individual. Cape Coast: UCC Press, 2002.

13 WHO, http://www.who.int/disability/worldreport/2011/report/en/index.html 2011

14 Padden, C. A. \& Humphries, T.L. "Inside Deaf Culture.” Cambridge, MA: Harvard University Press, (2005):1.

15 Ladd, P. "Understanding Deaf Culture, in search of deaf hood." Toronto:: Multilingual Hill press, 2013.

16 Lane, Harlan L., Richard Pillard, and Ulf Hedberg. "The people of the eye:Deaf Ethnicity and Ancestry.”. Oxford: Oxford University press, (2011): 269.
} 
include the use of interpreters or improved closed captioning systems. Many feel, however, that the social view fails to recognize the unique qualities of Deaf people and Deaf culture. They believe that this perspective asks Deaf people to fit and find their own way in a predominantly hearing society, instead of recognizing their own abilities and culture. ${ }^{17}$

Another perspective is referred to as the cultural-linguistic view. Supporters of Deaf Culture states that this perspective appropriately recognizes Deaf people as a minority culture in the world with their own language and social norms. ${ }^{18}$ This standpoint is believed to promote Deaf people's right to collective space within society to pass on their language and culture to future generations. Tomchin, opined that Deaf culture maintains certain rules of protocol that differ from what's considered socially acceptable. ${ }^{19}$ For example, in Hearing culture, a restaurant waiter must never touch a diner's shoulder. In Deaf culture, it's acceptable for a waiter to touch a diner's shoulder to get her attention. Similarly, it's okay for Deaf persons to maintain a steady gaze while they're signing to each other something that might be impermissible by Hearing standards.

\section{SPORTS, RECREATION AND SOCIETY}

Heap agrees that all cultural groups have social, recreational, and sports institutions that are organized to some degree and serve to foster group and communal loyalty and serve as a way to have fun within the boundaries of the community. ${ }^{20}$ Italian Americans have a popular urban sport called bocce, for example. Parochial schools and colleges have developed some formidable sports teams. Orthodox Jewish schools don't go in for football but have good baseball and basketball teams. Team sports, like volleyball, soccer and softball, play an important role in Deaf culture. Sports and physical activities are a way of expressing belonging and kinship in a kinetic way, free from communication barriers. ${ }^{21}$ According to Duchan, Deaf people enjoy participating in competitive sports with other Deaf people, and this predilection begins at school, where all the children participate and each one takes his/her turn. ${ }^{22}$ Tomchin concluded that although Olympic sports are an important part of U.S. culture (multi-billion-dollar industry), most deaf athletes prefer to participate in Deaf-only competitions (Deaf-lympics), despite the modest perks involved, the higher expenses, and the relative lack of prestige in Hearing culture. ${ }^{23}$ Since easy communication is of paramount importance, most Deaf athletes opt for Deaf sports.

Duchan, concurred that Deaf students in some mainstreamed settings may find themselves excluded from participation in intramural and university sports, due to the communication problems involved. ${ }^{24}$ This kind of exclusion doesn't exist at schools for the deaf. Every child, no matter how clumsy, gets a chance to participate. That's long been a defining characteristic of deaf culture. A few determined deaf athletes have participated in the "Hearing" Olympics.

\section{SPECIAL EDUCATION}

Special education and the setting up of special school's date back to the colonial days. ${ }^{25}$ Special schools are institutions that are organized to provide for the unique educational needs of special or exceptional children or learners. In Ghana, there are three categories of such schools; those for the blind, those for learners with hearing impairments, and those for the mentally retarded. It has been recorded that the education of the disabled in a school system started with the blind. Mention is made of Rev. Hunter who started some form of education for two blind boys in 1936. However, this school was officially opened in 1946 at Akropong Akuapem, in the Eastern Region. ${ }^{2}$

There are laudable objectives set for educating the disabled in Ghana. Ocloo asserted that schools for the disabled are set up primarily to educate in order to enable them live as normal as possible ${ }^{21}$. Their education is therefore meant to socialize and integrate them into the world of the able-bodied persons in order to foster mutual understanding between the non-disabled and the disabled individuals. They further reiterate that the schools strive to inculcate in these children both cognitive and vocational skills which can be marketable for their independent livelihood and sustenance. Avoke indicated that the practice of placing people with disabilities/deaf into segregated schools in Ghana is opposite the sociologist's view on institutionalization of the disabled and also against international policy on inclusive education. ${ }^{26}$ The education of the hearing impaired began on the $10^{\text {th }}$ of September 1957 at Osu in Accra. ${ }^{27}$ The organization came about when Rev Jackson Andrew Foster, a deaf Black American Missionary of the Christian Mission for the Deaf Africa

\footnotetext{
7 Tomchin, S. "Hearing the Needs of the Jewish Deaf." NY: Wiley \& son Ltd, (2012).

18 Heap, M.”Crossing social boundaries and dispersing social identity-Tracing deaf." Cape Town: University STLL Press Africa, (2013).

Tomchin, S. "Hearing the Needs of the Jewish Deaf."

Heap, M.”Crossing social boundaries and dispersing social identity-Tracing deaf." Cape Town: University STLL Press Africa, (2013).

Scott, M.G. “Analysis of human motion.” New York: F.S. Crofts \& Co. Inc. 5th Ed., (2005).

Duchan, J.F.\& Kovasrsky D. "Diagnosis as cultural practice.” Berlin, Germany: Mouton de-Gruyter, 2015.

Tomchin, S. "Hearing the Needs of the Jewish Deaf."

Duchan, J.F.\& Kovasrsky D. "Diagnosis as cultural practice."

Ocloo,. "Special Education.” Accra: City press, 2002.

Avoke, M. Special Eductional needs in Ghana: Practice and Research.

Grace, Y.G. "Education in Ghana and Special Needs Children."
} 
(CMDA) came to Ghana at the invitation of the Presbyterian Church of Ghana.

\section{Savelugu School for the Deaf}

The Savelugu School for the Deaf is one of the country's special schools providing education to hearing-impaired children. Established in March 1978 with (12) twelve students made up of seven (7) boys and five (5) girls. The school was initially set up as a unit under the Nyohini Rehabilitation Centre in Tamale but was subsequently moved to the Savelugu Middle Boarding School located at the outskirts of Savelugu. Since then, the school has provided formal education to many hearing-impaired children, particularly from the regions of the North. From the 2018/2019 academic records of the Savelugu school for the deaf, the school has a total population of 350 students comprising Kindergarten 43 pupils $($ boys $=22)($ girls $=21)$, Primary school 181 (boys $=104)($ girls $=77)$, Junior High School $126($ boys $=74)$ (girls $=52)$. The school has staff strength of twenty-seven $(27){ }^{28}$

\section{Benefit of Athletic Programmes to Students Living with Disability}

The benefits of athletic and physical education programs are equally important for students with disabilities as they are for all students. Akinsanmi, indicated that Physical activity is a key in addressing the obesity epidemic that is especially problematic for individuals with disabilities, $50 \%$ of people with disabilities do not engage in any physical activity ${ }^{29}$ Participating in physical activity helps reduce obesity and prevent health problems, such as heart disease, breast cancer and debilitating stress-related illnesses like depression. Akinsanmi, noted that individuals with disabilities who participate in sports have higher self-esteem, better body images and higher rates of academic success and are more likely to graduate from high school and matriculate in college; and experience greater career success and more options. ${ }^{30}$ Anamoah Mensah Committee report on education stated that, education should now focus on inculcating students with the skills and appreciation of the use of the hand as well as the mind to make students creative and production oriented (Meeting the Challenges of Education in the Twenty First Century, 2002).${ }^{31}$ Bailey ${ }^{32}$ DePauw \& Gavron,${ }^{33}$ indicated that people with disabilities are becoming more visible in our society than ever before. At least $15 \%$ of the world's population or (roughly 1 billion people) live with some form of disability. ${ }^{34}$ Of this percentage $2-4 \%$ (approximately 200 million people) experience significant difficulties in functioning, and these numbers are steadily increasing year by year. United Nations ${ }^{35} \&$ World Health Organization, ${ }^{36}$ agreed that treatment of people with disabilities has changed over the years; it may be due to the recognition of disability as a human rights issue. This has led to an increase in accessibility, availability and inclusion of programs and services for persons with a disability. Opportunities in Sports especially for people with disabilities will continue to increase. "Sport works to improve the inclusion and well - being of persons with disabilities in two ways - by changing what communities think and feel about persons with disabilities and by changing what persons with disabilities think and feel about themselves." ${ }^{\prime 37}$

\section{Disability Sport in Higher Education Curricular}

Mshelia, opined that sports in any society is an institution of considerable importance, which reflects societal values, belief system and needs as well as prescribed acceptable behavioural patterns for attaining and fulfilling those values and needs.$^{38}$ Mbaye, also defined sports to be a group of physical exercise that may be organized into individual or team game with somespecificrules. ${ }^{39}$ While Odejide, postulated that countries all over the world have used sports as means of nation building. ${ }^{40}$

Sallis, opined that traditionally, university and college faculties have emphasized discipline-based research, teaching, and service. ${ }^{41}$ This is also true in the academic discipline of sport management. As such, disability issues are often considered the exclusive province of specialty fields for rehabilitation counselors or special education professionals, and sub disciplines such as adapted physical education. Including knowledge about individuals with disabilities in the

\footnotetext{
Savelugu School for the Deaf, Staff Records Book, 2018.

Akinsanmi, T. "The roll of Exercise in promoting Health as perceived by health professionals."

Ibid.

Anamoah Mensah Committee report 2002

Bailey, S. In Athlete fisrt: a history of the Paralympic movement. London:: Wiley \& Sons.

DePauw, K.P. \& Gavron, S.I. “Disabilty and Sports.” London: Champaignll: Human Kinestics, 2011.

Grace, Y.G. "Education in Ghana and Special Needs Children."

United Nations, convention on the right of persons with disabilities facts.

WHO, http://www.who.int/disability/worldreport/2011/report/en/index.html 2011

Right to Play, Harnessing the power of sports for development. https://www.righttoplay.com/

Mshelia, B.S. "Dimensions and politics in Sports, 21stC and sports Develoment in Nigeria." Abuja: Academy sportspress, 40-54.

Mbaye, K. "Sports and Human rights." Geneva: Olympic Review.XXVI(24), 2015.

Odejide,Sports as an Essential Ingredient to National Development.

41 J. Sallis., "Environmental Influences on Physical Activity:Apllying Ecological Models.” 22-51. Abuja: Academy press, 2012.
} 
curricula is important. However, infusing knowledge about disability throughout the curricula should be the goal. ${ }^{42}$ According to Fabunimi, ${ }^{43}$ there are eight reasons for infusing information about disabilities into the general curriculum:

1. People with disabilities are one of the largest and least understood minority groups in the world.

2. Ignorance brings discrimination and stereotyping.

3. To eliminate stereotypes, we first have to see them and challenge the assumptions behind them.

4. Familiarity breeds comfort and not contempt.

5. We should recognize the important contributions people with disabilities have made throughout history.

6. Disability is part of the diversity we should celebrate in society.

7. Our literature, art, and popular entertainment are full of imagery and portray ill of disabilities.

8. Race, gender, and disability are related throughout history, 2009.

The infusion approach does not require the elimination of all coursework in sport for people with disabilities, rather information about sport and individuals with disabilities would be infused throughout the curricula. ${ }^{44}$

\section{Benefits of Infusion of sports/physical activity into disability curriculum}

Benefits of infusion apply to students with disabilities and society in general. Specific benefits of infusion include (a) increased knowledge and understanding of disability, individuals with disabilities, and issues of equity (b) increased commitment to disability issues and concerns of individuals with disabilities (c) increased collaboration among colleagues (d) acquisition of new skills (e) increased ownership and commitment to disability and elimination of stigma. ${ }^{45}$ Research indicates that the brain organizes information by seeking to perceive and create meaningful patterns and conversely, resists developing patterns from information which is isolated and unrelated. For maximum teaching effectiveness, a student should have the opportunity to create meaningful and personally relevant patterns within an integrated and experience-based curriculum.

\section{DETERMINANTS OF PARTICIPATION IN SPORTS/PHYSICAL ACTIVITIES}

According to Mbaye, the most frequently identified determinants of active participation of children with disabilities in sports and physical activities are the child's functional limitations, high costs, and lack of nearby facilities or programs. ${ }^{46}$ Mshelia indicated that adolescents with physical challenge cited the cost of specialized equipment as the most frequent reason for nonparticipation in sports activities. ${ }^{47}$

Participation of the deaf in sport have increased in recent years, nevertheless they still face many challenges because of their physical challenges. Apart from lack of access to appropriate facilities, safety, funds, technological aids, including sporting wheel chairs, prostheses, special materials for persons who are blind and sign language interpretation, they have to contend with negative attitude of the administrators, coaches and the public which often compound their problems. Moreover, inactive role models, competing demands and time pressures, unsafe environments, lack of adequate facilities, insufficient funds, and inadequate access to quality daily physical education seem to be more prevalent among populations with people with disabilities. Overall, environmental and family factors seem to be more significant determinants of participation than characteristics of the children themselves.

Oliver, asserted that individuals with disabilities especially the deaf are still, to a large extent, socially segregated and experience negative societal stereotypes and low performance expectations, rendering them with limited opportunities for participation in group physical activities. ${ }^{48}$ These attitudinal barriers in the community contribute to a lack of awareness regarding current programs and opportunities for participation. Although specialized programs are beneficial, the participation of children with disabilities in community activities can reduce societal barriers. It is a common misconception that children with disabilities are susceptible to trauma and, therefore, should avoid rigorous sporting activities that are typically associated with injury.

Although athletes who are deaf have rates of injury similar to those of other athletes, fear of injury frequently remains a barrier to participation. Overall, misconceptions and attitudinal barriers at the level of the individual, the family, and the community need to be addressed to integrate children of all abilities into recreational and sporting

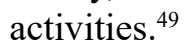

Opportunities exist in many countries, at the grassroots level through to elite competition for people with disabilities especially the deaf to showcase their abilities in the domain of sport and physical activity. However, this

\footnotetext{
42 Mbaye, K. "Sports and Human rights." Geneva: Olympic Review.XXVI(24), 2015.

43 Fabunimi, B.Y. "Recreation thruogh Recreation: The real future." Lagos: Toklas Enterprise, Inc Ajala Ed

44 Kowalski, E.M. "Theinfusion approach to Teacher development." 49-54. NY: CA: SAGE, 2014.

45 Rizzo, T.I.Broadhead,G.D \& Kowalski, E. “Changing kinesiology and physical Education.”. Lagos: Quest 49, (2010):229-237

4 Mbaye, K. "Sports and Human rights." Geneva: Olympic Review.XXVI(24), 2015.

7 Mshelia, B.S. "Dimensions and politics in Sports, 21 stC and sports Develoment in Nigeria."

48 Oliver, M. "The politics of Disablement."(Basingstoke: MacMillan,2014).

49 Gill, J. "Sports and the ageing Population: Do older people have a place in driving up participation in sports." London: SAGE, (2011).
} 
is not uniform around the world and whilst there has been progress and positive change in quality of life for people with disabilities in many developed countries, often this progress is not reflected in developing countries. ${ }^{50}$ People with disabilities indeveloping countries face major barriers that limit their access to and participation in sport and physical activity. Within a development context, these barriers impact on both the building up of activity pathways for people with disabilities in developing countries and on the use of sport and physical activity programmes for wider developmental goals.

\section{The Right to Participate}

Physical education is a generally mandated component of special education services, including the promotion of physical and motor fitness, fundamental motor skills, and skills in individual and group games and sports. ${ }^{51}$ Pediatricians and parents of children with physical challenge can advocate for programs of adapted physical education and recreation in each child's individualized education plan. Schools are required to modify programs or activities according to the abilities of each child. Students with physical challenge have the same right as all students to compete for inclusion on interscholastic teams that use performance criteria to determine who will participate. The combined advocacy efforts of well-informed pediatricians, parents, educators, and others are needed to ensure and promote the participation of all children in sports and physical activity programs, each according to his or her abilities.

Drake also agreed that Persons with hearing challenges are generally excluded from education, employment and community life from a younger age.$^{52}$ Exclusion deprives them of opportunities to engage and develop relationships with others. Sport is well suited to helping persons with physical challenge acquire social skills they may be lacking. It teaches individuals how to communicate effectively as well as the significance of teamwork and cooperation, goalsetting, self-discipline, respect for others, and the importance of rules. ${ }^{53}$ Sport also enables persons with physical challenge to take risks and learn how to manage failure and success in a safe and supportive environment. Coaches and teammates provide important role models and can help persons with hearing impaired to develop skills they can apply in other aspects of their lives, such as employment. ${ }^{54}$ Sports universal popularity makes it ideal for fostering social interaction, even in remote areas. By bringing together people with similar physical challenge, sport contributes to normalization enabling persons with physical challenge to share their experiences and enjoy with others who understand their challenges and capacities.

According to Moschetti, the deaf can play and win in sports. ${ }^{55}$ Modern sports have changed to accommodate deaf athletes. In swimming or track, instead of hearing the signal to start, deaf athletes look for a flashing light or a waving flag. ${ }^{56}$ In baseball, the umpire yells and signs outs, strikes, and balls. Deaf athletes have proven they can compete and win in amateur sports, deaf-only leagues, and pro-sports at the highest level. In sports, the most critical senses are vision, touch, and hearing. So, it would seem as if deaf people have only two-thirds of the active senses of hearing people, and therefore are at a competitive disadvantage. Right to play indicated that this can be proven wrong for two reasons

1. Deaf athletes can heighten their senses of touch and vision to concentrate deeper and longer than hearing athletes.

2. For everyone else, hearing can be a weakness if it makes us focus on the wrong sounds Ogedengbe, concur that winning, in any individual or team sport, boils down not to the physical or external, but to the mental and internal faculties. Most professional coaches, players, and trainers believe that the difference between great performance and average or poor performance is not skill, but deep concentration. ${ }^{57}$

\section{METHODOLOGY}

The study used a survey research design, aimed at determining participating factors in Physical Education/sporting activities of the deaf in Savelugu School for the Deaf.

\footnotetext{
50 Tsai, C.Y. "Travel Constrains and travel behaviours for Physically challenged." Abuja: J. Sports (2010).

Drake, R.F. "The Exclusion of Physically challenged.” Baltimore: Paul H. Brooks, (2014).

2 Drake, R.F. "The Exclusion of Physically challenged."

53 Hutzler, Y.\& Sherrill, C. "Physically Challenged, physical activity, Psychological Well-being and Empowerment." p281-300. Morgantown: In:Lidor. Fitness Information Center, 2010.

54 Block, M.E. A Teachers guide to including Students with Physically Challenged in general Physical Education. Baltimore: Paul H. Brooks, 2010.

55 Moschetti,“The Determinants of Sport Participation in Switzerland.”259-276.

56 Ibid.

57 Ogedengbe, D.O. “Determinants for effective management of school sports in universal Basic Education in Nigeria." Lagos: Sports Mgt Press.1-3
} 


\section{Population, Sample Selection and Sample Size}

The total population of the school was $350 .{ }^{58}$ From the 2018/2019 academic records of Savelugu school for the deaf, the school has a total population of 350 students comprising Kindergarten 43 pupils (boys $=22$ ) (girls $=21$ ), Primary school 181 (boys $=104)($ girls $=77)$, Junior High School $126($ boys $=74)($ girls $=52)$. The school has staff strength of twenty-seven (27). A convenient sampling technique was used to select the respondents from the rest of the students. It was preferred because the subjects were easiest to recruit, accessible and proximity for the study and the researcher. It is also preferred for its fast data collection approach. Not all the 350 students were selected for the study, but all Junior High School students were purposively sampled and used for the study. This sampling technique was used to select participants who could read properly and answer the questionnaire. However, there were a few things that also informed the sample size:

- Time

- Population size

- The interest of the population

- Consanguinity of the population

\section{Data collection approach/instruments}

A data collection instrument (questionnaire) was developed, validated and used. Both qualitative and quantitative data was collected for the study. Data collection is an important aspect of any type of research study. Inaccurate data collection can impact the results of any study. A panel of experts reviewed the instrument and approved it for use. The questionnaires were distributed manually for students to answer. Information were recorded in a field record notebook and codes assigned to each of them to ensure accurate referencing when an error occurs. Data collected were analyzed using SPSS to obtain descriptive statistics (mean, mode and median).

\section{RESULTS AND DICUSSIONS}

In all one hundred and fifty (150) open ended and closed ended questionnaire were sent out and one hundred twentyfour (124) retrieved. Out of the number fifty-one (51) representing (41.12\%) were girls and seventy-three (73) also representing (58.87\%) were boys. In answering a question on whether they have physical education on the timetable. $124(100 \%)$ of the respondents agreed that physical education is not on their timetable. This assertion goes to defeat the opinion of Kowalski who indicated that, for maximum teaching effectiveness, a student should have the opportunity to create meaningful and personally relevant patterns within an integrated and experience-based curriculum. The result reveals that this is lacking in Savelugu School for the deaf curriculum.

Table 1 shows the number of times for physical education activities in the school. The results indicated that $66.7 \%$ (84) of the respondents agree that Physical education activities are not structured in Savelugu School for the Deaf. However, $16.9 \%$ (21) of them agreed that they participate in physical activities once a week. Meanwhile $7.9 \%$ (10) and 5.6\% (7) do agree that they participate in physical activities two and three times a week respectively. This displayed a mix feeling among the respondents. The results go a long way to buttress the point of Tsai, who indicated that people with disabilities in developing countries face major barriers that limit their access to and participation in sport and physical activity. ${ }^{59}$

Table 1: Number of times for PE Activities in the School

\begin{tabular}{lrrrr}
\hline & Frequency & Percent & Valid Percent & $\begin{array}{c}\text { Cumulative } \\
\text { Percent }\end{array}$ \\
\hline 1 & 21 & 16.7 & 16.9 & 16.9 \\
2 & 10 & 7.9 & 8.1 & 25.0 \\
3 & 7 & 5.6 & 5.6 & 30.6 \\
4 ABOVE & 2 & 1.6 & 1.6 & \\
NOT & & & & \\
STRUCTURED & 84 & 66.7 & 67.7 & \\
CAN BE DONE AT & & & & \\
ANYTIME & 124 & 98.4 & 100.0 & \\
Total & & & & \\
& & & & \\
\end{tabular}

\footnotetext{
Total

100.0

58 Savelugu School for the Deaf.2018/2019 academic records
59 Tsai, C.Y. "Travel Constrains and travel behaviours for Physically challenged." Abuja: J. Sports, 2010
} 
Drake, opined that Physical activity/sports is a generally mandated component of special education services, including the promotion of physical and motor fitness, fundamental motor skills, and skills in individual and group games and sports. The field results (Table 2) supports the assertion of Drake as indicated in the literature.91.9\% (114) of the respondents agreed that they have the right to play and $8.1 \%$ (10) disagree to the statement. It could be that they are not properly informed about their rights or otherwise.

Table 2: Right to play

\begin{tabular}{ccccc}
\hline & Frequency & Percent & $\begin{array}{c}\text { Valid } \\
\text { Percent }\end{array}$ & $\begin{array}{c}\text { Cumulative } \\
\text { Percent }\end{array}$ \\
\hline YES & 114 & 90.5 & 91.9 & 91.9 \\
NO & 10 & 7.9 & 8.1 & 100.0 \\
Total & 124 & 98.4 & 100.0 & \\
\hline
\end{tabular}

Total

$126 \quad 100.0$

Table 3 indicates how the deaf (hearing impaired) are given the chance to exhibit their talents in the school during physical education activities. The results indicate that 71 of respondents representing $57.3 \%$ agreed that they partially are given the opportunity to exhibit their skills during physical activity/sports time. 37 (29.8\%) also agreed that they are always given the opportunity to exhibit their skills. $16(12.9 \%)$ of the respondents also indicated that they are not given the opportunity at all to exhibit their skills. This result defeat the assertion of Moschetti, who indicated that, the deaf can play and win in sports. Modern sports have changed to accommodate deaf athletes and all other physical challenged persons.

Table 3: Opportunity to Exhibit Talents

\begin{tabular}{lllll}
\hline & Frequency & Percent & $\begin{array}{l}\text { Valid } \\
\text { Percent }\end{array}$ & $\begin{array}{l}\text { Cumulative } \\
\text { Percent }\end{array}$ \\
\hline PARTIALLY & 71 & 57.3 & 57.3 \\
ALWAYS & 37 & 29.8 & 87.1 \\
NOT AT ALL & 16 & 12.9 & \\
\hline Total & 124 & 100 & 100
\end{tabular}

In the area of safe facilities table 4 indicates that $47.6 \%$ (59) agreed that they have safe facilities in the school. $44.4 \%$ (55) said the facilities are partially safe and 8.1\% (10) of the respondents disagree. Safety of pupils in schools is paramount to every administrator. This result also agrees with $\mathrm{Mbaye}^{60}$ who contended that apart from lack of access to appropriate facilities, safety is also a determinant of participation in sporting activities by the deaf.

Table 4: Are Your Facilities safe For PE Activities

\begin{tabular}{ccccc}
\hline & Frequency & Percent & $\begin{array}{c}\text { Valid } \\
\text { Percent }\end{array}$ & $\begin{array}{c}\text { Cumulative } \\
\text { Percent }\end{array}$ \\
\hline YES & 59 & 46.8 & 47.6 & 47.6 \\
NO & 10 & 7.9 & 8.1 & 55.6 \\
PARTIALLY & 55 & 43.7 & 44.4 & 100.0 \\
\hline Total & 124 & & 100.0 &
\end{tabular}

The question on what benefits can be driven from participation in physical education activities, $91 \%$ of the respondents indicated the following; a) it improves on their lifestyles. b) it improves on facilities and equipments, c) it promotes fundamental motor skills, d) promotion of physical fitness, e) the spirit of belongingness, f) socialization/collaborative work, g) it enhances academic work. These results buttress the point of Odejide, ${ }^{61}$ who opined that an ideal physical activity/sports program would be one that focuses on aspects leading to lifelong participation in and enjoyment of physical activity accompanied by appropriate fitness levels. He again emphasized that, physical education classes are

\footnotetext{
${ }_{60}$ Mbaye, K. "Sports and Human rights."

${ }_{61}$ Odejide, Sports as an Essential Ingredient to National Development.34- 40
} 
the only physical activity that many children receive throughout the day, and without them, an even greater number of children, including those who are deaf and physically challenged would be prone to aspects associated with sedentary lifestyles and diseases. Schools need to involve their students in daily physical education classes. The emphasis of such a program should be placed on promoting physical fitness and developing skills that lead to a lifelong enjoyment of physical activity and healthy lifestyles of the deaf.

The preference of a physical activity/sports type may be determined by variables such as personal preference, characteristics of the sport, medical condition, availability of the facilities (equipment, appropriate coaching), cognitive ability and social skills of the person. ${ }^{62}$ Physical activity/sports play an important role in our schools; there are a growing number of studies examining the factors affecting participation in physical activity in well-developed countries. Humbert et al, stated that many options are available when it comes to good sport and the most important factor in preference will be determining which sport to enjoy the most. ${ }^{63}$ The results revealed the following as what determines their participation in physical activities in Savelugu School for the Deaf. 1) Unsafe environment, 2) family factors, 3) inactive role models, 4) cost of equipments. 5) Sports Facilities/equipment, 6) attraction towards the activity 7) support from significant others. Sports Facilities in the School as revealed by the field data showed that, the most available sport facilities were football field and volleyball courts, both rated at $46.7 \%$. There was a Merry-go-round facility donated to the school by Right to play which is also at $18.4 \%$, athletics fields $(22.6 \%)$. However, the school has no well qualified or trained physical education teacher, no hand ball court and a basketball court. These findings confirm that significantly there are common available sports facilities in both the deaf and the regular schools.

Culturally, the concept of disability has been examined from various cultural perspectives across the continent of Africa and found in every culture, disability is perceived differently, and such difference shapes the kind of services rendered to them. Culture can be seen as a "construction" of reversible reaction ${ }^{64}$ Cultural understanding is also shaped by the meanings attached to various behaviours by the social and economic organization of a given society, or by other internal and external cultural dynamics, a culture imposes standards upon all citizens of that given culture.

Table 5 indicates how the Deaf in Savelugu School for the Deaf feel segregated by others in the community. The results reveal that 118 representing $95.2 \%$ agreed Yes that they are being segregated against, $4.8 \%$ (6) also indicated No, meaning no segregation against them. Segregation can certainly harm children with disabilities. But it can also cause negative consequences for children and adults without disabilities and our society-at-large. ${ }^{65}$ When children with disabilities are excluded from participation in ordinary environments, children without disabilities have no opportunities to get to know them, to see them as their peers/equals, and/or to see beyond the disability. Thus, they're ignorant that children with disabilities are children, first, and are more like them than different

Table 5: Segregation among the Deaf

\begin{tabular}{lcrr}
\hline & & Frequency & Valid Percent \\
\hline & YES & 118 & 95.2 \\
& NO & 6 & 4.8 \\
\hline Total & & 124 & 100.0
\end{tabular}

\section{CONCLUSION}

Based on the findings, the authors concluded that the availability of sports facilities and equipment is a significant determinant for the Deaf to participate in physical activities/sports. Funding is a significant determinant for the Deaf in participation in physical activities/sports programmes in the school. Sports programme is a significant determinant for the Deaf to participate in physical activities/sports in Savelugu School for the Deaf. Role models also play a significant role in determining participation in physical activities/sports in Savelugu School for the Deaf. The study provides us an opportunity to gain insight on how exposed or porous schools for the Deaf are in Ghana in terms of physical/sports activities.

\section{Recommendations}

The authors recommend that the Ministry of Education (Special Education Unit of Ghana Education Service) should

\footnotetext{
62 Salman, N.\& Naz S. "Motivational factors influencing the participartion of students with hearing impairment in Sports activities." Journal of contemporary research in Business Vol.3. No12, 2012 (April): 481-488.

63 Humbert, M.I.Chad, K.F. Spink,K.S. Muhajarine, N. Anderson,K.D. Factors that influence Physical activity participation among high and low SES. Lagos: Academy of sports press,(2016).

${ }_{64}$ Murphy, R. The body silent.(New York: Norton Press, 2009.)

65 Kathie, S. The moral Imperative of Inclusion: Lessons of Segregation.(London: BravelHeart Press., 2011).
} 
monitor the allocation of funds and utilization of physical activities/sports programmes in School for the deaf (Savelugu) and the entire nation. Adequate qualified physical education professionals must be sent to the school to help the deaf determine their sports talents. Adequate modern and modified sports facilities and equipment in the special schools should be provided. More role models must be made to visit the school regularly to assist in physical Education activities and sports. Adequate information and guidelines on the use of sports facilities and equipment in Deaf schools. Teachers must provide videos and pictures of world class para-lympians in Special Olympics in Deaf schools.

\section{BIBILIOGRAPHY}

Akinsanmi, T. "The roll of Exercise in promoting Health as perceived by health professionals." 34-40. Journal of Reseach in Behavioural Sciences 1(2).(2015).

Anamoah Mensah Committee report, 2002

Avoke, M. "Introduction to special education for Universities and Colleges." 1-5, 79-84. Accra-Ghana: City Publishers, 1997.

Avoke, M. Special Educational Needs in Ghana: Practice and Research. Winneba: Special Education books, city press, 2005.

Babbie, E.R. "Survey Research Methods." USA, California: SAGE, 2013.

Bailey, S. In Athlete fist: a history of the Paralympic movement. London:: Wiley \& Sons.

Block, M.E. A Teachers guide to including Students with Physically Challenged in general Physical Education. Baltimore: Paul H. Brooks, 2010.

DePauw, K.P. \& Gavron, S.I. "Disabilty and Sports.” London: Champaignll: Human Kinestics, 2011.

Drake, R.F. "The Exclusion of Physically challenged." Baltimore: Paul H. Brooks, 2014.

Duchan, J.F.\& Kovasrsky D. "Diagnosis as cultural practice.” Berlin, Germany: Mouton de-Gruyter, 2015.

Fabunimi, B.Y. "Recreation thruogh Recreation: The real future." Lagos: Toklas Enterprise, Inc Ajala Ed, 2009.

Gill, J. "Sports and the ageing Population: Do older people have a place in driving up participation in sports." London: SAGE, 2011.

Grace, Y.G. "Education in Ghana and Special Needs Children." Accra: City press Accra North, 1998.

Heap, M. "Crossing social boundaries and dispersing social identity-Tracing deaf." Cape Town: University STLL Press Africa, 2013.

Heward, W. I. \& Orlansky M.D. Exceptional Children. NY: Mirrill McMillan 4th Ed, 1992.

Humbert, M.I.Chad, K.F. Spink,K.S. Muhajarine, N. Anderson,K.D. Factors that influence Physical activity participation among high and low SES. Lagos: Academy of sports press., 2016.

Hutzler, Y.\& Sherrill, C. "Physically Challenged, physical activity, Psychological Well-being and Empowerment." p281-300. Morgantown: In:Lidor. Fitness Information Center, 2010.

Kathie, S. The moral Imperative of Inclusion: Lessons of Segregation. London: BravelHeart Press., 2011.

Karma, K.J. “Research.” London: Willey \& Sons, 2008.

Kothari, C.R. "Research Methodology.” Jalpur-New Delhi - India: New Age Publishers 2nd Ed, 2004.

Kowalski, E.M. "Theinfusion approach to Teacher development." 49-54. NY: CA: SAGE, 2014.

Kvale, S., \& Brinkmann, S. Interviews: Learning the craft of qualitative research interviewing (2 ${ }^{\text {nd }}$ ed.). Thousand Oaks, CA: SAGE.2009

Ladd, P. "Understanding Deaf Culture, in search of deaf hood." Toronto:: Multilingual Hill press, 2013.

Lane, Harlan L., Richard Pillard, and Ulf Hedberg. "The people of the eye:Deaf Ethnicity and Ancestry." p269.

Oxford: Oxford University press, 2011.

Mbaye, K. "Sports and Human rights." 24. Geneva: Olympic Review.XXVI(24), 2015.

McWilliam, H.O.A. \& Kwamena-Poh, M.A. The development of Education in Ghana. London U.K: Longman group Ltd pp41-52, 1975.

Millar, D. F. "Quantitative and Qualitative." California: SAGE; CA, 1991.

Moschetti, “The Determinants of Sport Participation in Switzerland. "Schweizer ZeitschriftFürSoziologie, 36, (2010): 259-276.

Mshelia, B.S. "Dimensions and politics in Sports, 21 stC and sports Develoment in Nigeria." pp40-54. Abuja: Academy sports press.

Murphy, R. The body silent. New York: Norton Press, 2009.

Ocloo,. "Special Education." Accra: City press, 2002.

Odejide, Sports as an Essential Ingredient to National Development. Journal of The Nigeria Academy of Sports Administration 1. (2012):34- 40 
Ogedengbe, D.O. "Determinants for effective management of school sports in universal Basic Education in Nigeria." 1-3. Lagos: Sports mgt Press.

Oliver, M. “The politics of Disablement.” Basingstoke: MacMillan, 2014.

Padden, C. A. \& Humphries, T.L. "Inside Deaf Culture.” p1. Cambridge, MA: Harvard University Press, 2005.

Prosper, D. \& Gyimah, E. Educating the Special individual. Cape Coast: UCC Press, 2002.

Right to Play, Harnessing the power of sports for development. http://www.righttoplay.com

Rizzo, T.I.Broadhead,G.D \& Kowalski, E. “Changing kinesiology and physical Education.” 229-237. Lagos: Quest 49, 2010.

Sallis, J.F. “Environmental Influences on Physical Activity:Apllying Ecological Models.” 22-51. Abuja: Academy press, 2012.

Salman, N.\& Naz S. "Motivational factors influencing the participartion of students with hearing impairment in Sports activities." Journal of contemporary research in Business Vol.3. No12, 2012 April: 481-488.

Savelugu School for the deaf staff records book 2018.

Scott, M.G. "Analysis of human motion." New York: F.S. Crofts \& Co. Inc. 5th Ed., 2005.

Tomchin, S. "Hearing the Needs of the Jewish Deaf-." NY: Wiley \& son Ltd, 2011

Tsai, C.Y. "Travel Constrains and travel behaviours for Physically challenged." Abuja: J. Sports, 2010

United Nations, Convention on the right of persons with disabilities facts. http://www.un.org/disabilities/. June 2006. (accessed 2006).

WHO. Designing the road to better Health. Constitution, NY: Hasting center 21, 1948.

WHO, Disability Report. https://www.who.int/disabilities/world_report/2011/report/en/ 